Force measurement using strain-gauge balance in a shock tunnel with long test duration

Yunpeng Wang, Yunfeng Liu, Changtong Luo, and Zonglin Jiang

Citation: Review of Scientific Instruments 87, 055108 (2016); doi: 10.1063/1.4950781

View online: http://dx.doi.org/10.1063/1.4950781

View Table of Contents: http://aip.scitation.org/toc/rsi/87/5

Published by the American Institute of Physics

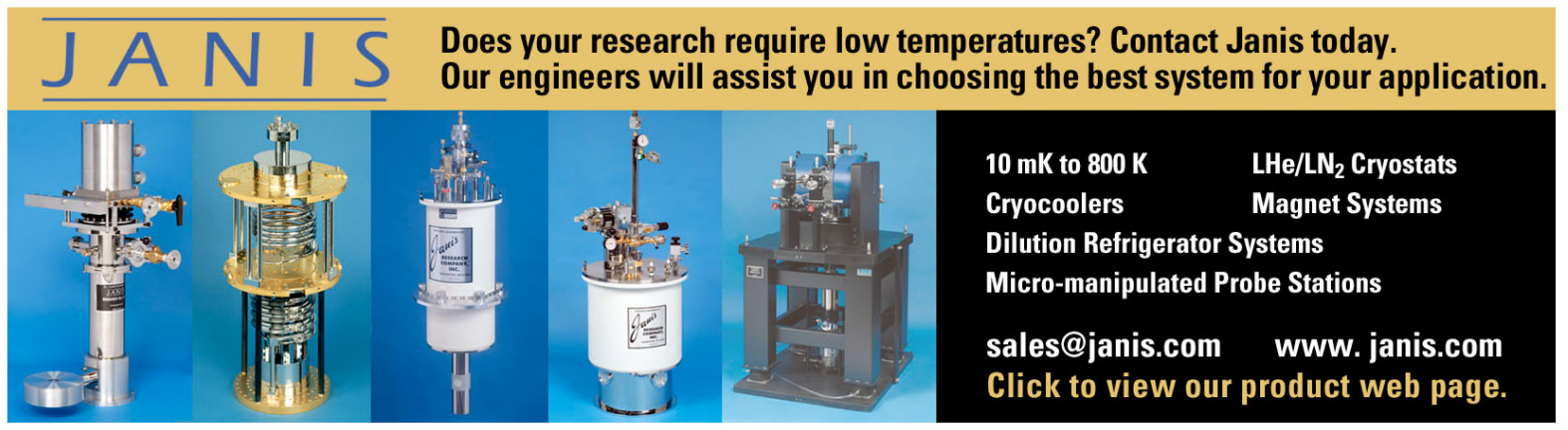




\title{
Force measurement using strain-gauge balance in a shock tunnel with long test duration
}

\author{
Yunpeng Wang, ${ }^{\text {a) }}$ Yunfeng Liu, Changtong Luo, and Zonglin Jiang \\ State Key Laboratory of High Temperature Gas Dynamics (LHD), Institute of Mechanics, Chinese Academy \\ of Sciences, Beijing 100190, China
}

(Received 27 February 2016; accepted 2 May 2016; published online 24 May 2016)

\begin{abstract}
Force tests were conducted at the long-duration-test shock tunnel JF12, which has been designed and built in the Institute of Mechanics, Chinese Academy of Sciences. The performance tests demonstrated that this facility is capable of reproducing a flow of dry air at Mach numbers from 5 to 9 at more than $100 \mathrm{~ms}$ test duration. Therefore, the traditional internal strain-gauge balance was considered for the force tests use in this large impulse facility. However, when the force tests are conducted in a shock tunnel, the inertial forces lead to low-frequency vibrations of the test model and its motion cannot be addressed through digital filtering because a sufficient number of cycles cannot be found during a shock tunnel run. The post-processing of the balance signal thus becomes extremely difficult when an averaging method is employed. Therefore, the force measurement encounters many problems in an impulse facility, particularly for large and heavy models. The objective of the present study is to develop pulse-type sting balance by using a strain-gauge sensor that can be applied in the force measurement of $100 \mathrm{~ms}$ test time, especially for the force test of the large-scale model. Different structures of the S-series (i.e., sting shaped balances) strain-gauge balance are proposed and designed, and the measuring elements are further optimized to overcome the difficulties encountered during the measurement of aerodynamic force in a shock tunnel. In addition, the force tests were conducted using two large-scale test models in JF12 and the S-series strain-gauge balances show good performance in the force measurements during the $100 \mathrm{~ms}$ test time. Published by AIP Publishing. [http://dx.doi.org/10.1063/1.4950781]
\end{abstract}

\section{NOMENCLATURE}

$B_{0} \quad=$ bias limit of some parameter

$C_{A} \quad=$ axial force coefficient

$C_{N} \quad=$ normal force coefficient

$C_{M} \quad=$ pitching moment coefficient

$D \quad=$ cone's bottom diameter, $\mathrm{m}$

$L \quad=$ reference length (model length), $\mathrm{m}$

$M_{x} \quad=$ rolling moment, $\mathrm{Nm}$

$M_{y} \quad$ = yawing moment, $\mathrm{N} \mathrm{m}$

$M_{z} \quad=$ pitching moment, $\mathrm{N} \mathrm{m}$

$M_{\infty} \quad=$ uniform flow Mach number

$P_{0} \quad=$ stagnation pressure, $\mathrm{MPa}$

$P t \quad=$ Pitot pressure, $\mathrm{kPa}$

$P_{()} \quad=$ precision limit of some parameter

$q \quad=$ dynamic pressure, $\mathrm{Pa}$

Re = unit Reynolds number, $1 / \mathrm{m}$

$S \quad=$ reference area, $\frac{\pi D^{2}}{4}, \mathrm{~m}^{2}$

$t=$ time, $\mathrm{ms}$

$T_{0} \quad=$ stagnation temperature, $\mathrm{K}$

$U_{()} \quad=$ uncertainty of some parameter

$X \quad=$ axial force, $\mathrm{N}$

$Y \quad=$ normal force, $\mathrm{N}$

$Z \quad=$ side force, $\mathrm{N}$

$\alpha \quad=$ nominal angle of attack, ${ }^{\circ}$

$\varepsilon_{\text {ave }}=$ averaged strain, $\mu \varepsilon$

$\sigma_{0} \quad=$ standard deviation of some parameter

\section{INTRODUCTION}

For a conventional hypersonic shock tunnel, owing to instantaneous flow field and short test time (generally $500 \mu \mathrm{s}-20 \mathrm{~ms}),{ }^{1-4}$ the mechanical vibration of the modelbalance-support (MBS) system occurs and cannot be damped during a shock tunnel run. For the MBS system, the lowest natural frequency of $1 \mathrm{kHz}$ is sometimes required for the test time of typically $5 \mathrm{~ms}$ to obtain improved measurement results. $^{2}$ The higher the natural frequencies, the better the justification for the neglected acceleration compensation. For such test conditions, many researchers proposed several special balances to measure the aerodynamic forces in the impulse facilities, that is, accelerometer balance, ${ }^{5-7}$ stress-wave force balance, ${ }^{8-10}$ free-flight measurement technique, ${ }^{11-16}$ and compensated balance. ${ }^{17}$ Owing to the very short test time, however, the mature technology was undeveloped for the force measurements in a shock tunnel.

The hypersonic detonation-driven shock tunnel with long test duration, JF12, was developed based on the backwardrunning detonation driver technique. Its performance tests demonstrated that the facility is capable of reproducing the pure airflow with Mach numbers from 5 to 9 at altitude of $25-50 \mathrm{~km}$ with $100 \mathrm{~ms}$ test duration. Figure 1 shows schematically the entire system of the JF12 hypersonic shock tunnel. From right to left, the first part is the vacuum system for damping wave reflection during the nozzle starting process. The second part is the test section, which is $15 \mathrm{~m}$ in length and $3.5 \mathrm{~m}$ in diameter at the outlet. The contoured nozzle is $15 \mathrm{~m}$ in length and $2.5 \mathrm{~m}$ in diameter, and another nozzle is smaller,

\footnotetext{
a)Electronic mail: wangyunpeng @imech.ac.cn
} 


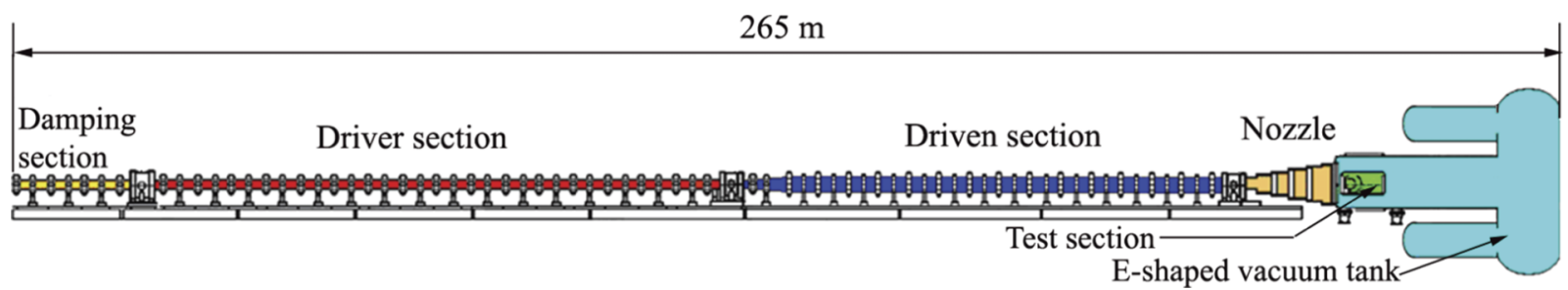

FIG. 1. Schematic of JF12 hypersonic detonation-driven shock tunnel.

having an exit of $1.5 \mathrm{~m}$ in diameter for Mach number of 5-7. Next to the nozzle, there is the driven section, which is $89 \mathrm{~m}$ in length and $720 \mathrm{~mm}$ in diameter. The detonation driver is $99 \mathrm{~m}$ in length and $400 \mathrm{~mm}$ in diameter. The driver operates in the backward-running detonation mode, that is, the detonation is ignited at its right end. The detonation driver and the driven section are connected with the transition component by which the tube diameter is gradually reduced from 720 to $400 \mathrm{~mm}$. Between the detonation driver and the transition component, there is the diaphragm rig that is used to produce the incident shock wave in the shock tunnel after the direct detonation initiation. The damping section is located at the far left end of the facility and is $19 \mathrm{~m}$ in length and $400 \mathrm{~mm}$ in diameter.

Based on test duration of more than $100 \mathrm{~ms}$, the stiff construction balance, that is, the traditional internal straingauge balance (SGB), was considered for use in the force test in the JF12 long-test-duration impulse facility because of its mature technology and low cost of the strain-gauge. However, when the force test is conducted in a shock tunnel, the inertial forces lead to low-frequency vibrations of the model and its motion cannot be addressed through digital filtering because a sufficient number of cycles cannot be found during a shock tunnel run. This condition implies restriction on the model size and mass as its natural frequencies are inversely proportional the length scale of the model. Based on these technical difficulties, S-series (sting-series) pulse-type SGBs were proposed and the measuring element structure of SGB was optimized by finite element method (FEM). The maximum loads (i.e., normal force) are from $500 \mathrm{~N}$ to $12000 \mathrm{~N}$ for the test models with different scales. The finite element computations were performed to analyze the vibrational characteristics of the MBS system to ensure enough cycles of the balance signal and high measuring sensitivity, especially axial element structure, during the $100 \mathrm{~ms}$ test. In addition, the force tests were conducted by using two large-scale cones. The S-series SGBs show good performance and the frequencies of the MBS system increase as a result of the stiff construction of SGB.

\section{S-SERIES PULSE-TYPE STRAIN-GAUGE BALANCES}

We used the strain-gauge sensor to measure the aerodynamic loads in the JF12 shock tunnel. The strain-gauge sensor has enough high-frequency response for the force test during a test period of more than $100 \mathrm{~ms}$. Our experimental and computational results show that the SGB, with the optimized structures, can be used in this long-test-duration shock tunnel. Therefore, S-series pulse-type SGBs were designed and fabricated for the force tests of JF12.
The technical data of balances JF12-ISG3-D053-S01 (hereafter referred to as S01) and JF12-ISG6-D106-S03-II (S03-II), which are the typical balances used in the JF12 shock tunnel, are shown in Table I. In this paper, S01 and S03-II are described in detail as the examples of S-series pulse-type SGB. The difference between S01 and S03-II is the element structure of axial load. The balance S01 was further optimized in the aspect of the measuring element of the axial load based on the axial element of S03-II. The performances of S01 and S03-II were examined to determine which type is better for the force measurement in the JF12 shock tunnel.

Figure 2 shows a schematic of two types of the SGB and their measuring element details. As shown in Table I and Figure 2, two balances have the same joints and overall structures. S01 has the same structure as S03-II, except the axial measuring element. All the SGBs use only one rectangular beam to measure the components of normal force, side force, yawing moment, and pitching moment. The moment center is located at the center of the rectangular beam. The first one marked S01 is a three-component (i.e., axial force, normal force, and pitching moment) sting balance and the S03-II is the six-component one. Based on the structures of S-series SGB, therefore, four strain-gauges are used for the axial load element in the case of S01 and eight strain-gauges for the S03II. These strain-gauge sensors are arranged in a Wheatstone bridge to measure the strain produced by the loads. The output voltage of a balance bridge changes as a function of the strain at the bridge location produced by the applied loads. Table II provides details of the load range for two balances used in the present study. The S-series balances with different limited loads are used for the test models with different scales. In the present study, the largest model is a cone with a length of $1.5 \mathrm{~m}$. More details of the test model employed in this study can be found in Section V. The performance of two sting SGBs was compared and analyzed through finite element simulation and force test in JF12.

\section{DESIGN AND OPTIMIZATION OF S-SERIES SGBS}

To design and construct a high-stiffness SGB that can meet certain demands, all aspects of the balance technology must be investigated. In this study, only the structure of SGB

TABLE I. Technical data on S-series SGBs (mm).

\begin{tabular}{lllcl}
\hline \hline Serial no. & Type & Components & Diameter & Length \\
\hline S01 & Sting & Three & 53 & 202.5 \\
S03-II & Sting & Six & 106 & 315 \\
\hline \hline
\end{tabular}




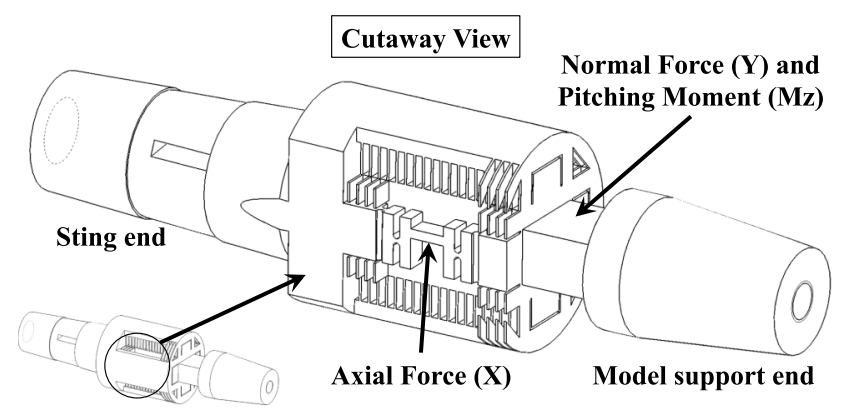

(a)

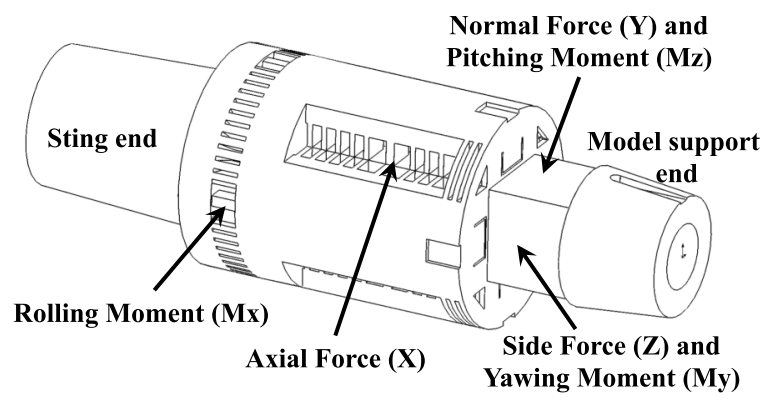

(b)

FIG. 2. Diagrams of the pulse-type SGBs and details of the measuring element. (a) Balance S01 (П-beam for the axial force element) and (b) Balance S03-II (I-beam for the axial force element).

is considered. From the point of view of structure, these high demands on the balance can be expressed as (1) low interference between each element; (2) high stiffness; (3) low stress level at the strain-gauge positions and related parts; and (4) capability to tolerate errors from the temperature gradients. Among these demands, the important properties for this transport type balance, such as the stiffness, the sensitivity, and the interference, were investigated in the present study. The computational and experimental results show that the SGB still has plenty of scope for structural improvement to achieve higher measurement accuracy, especially that of the axial force component.

Owing to the same rectangular beam for measuring $Y, Z$, $M_{y}$, and $M_{z}$, the present study focuses on the design and optimization in the axial element structure. Sections III A-III C show how to design and optimize the axial measuring element.

\section{A. Structural design and optimization}

Compared with other measuring elements, the axial force element is extremely difficult to design because of its complicated structure. For the impulse facility, several researchers have measured the axial force using the special balance. The main reason is that the test time is very short so that enough cycles cannot be found during a shock tunnel run. In this study,

TABLE II. Simultaneous component load ranges (N/N m).

\begin{tabular}{lcrcccc}
\hline \hline Serial no. & $X$ & $Y$ & $Z$ & $M_{x}$ & $M_{y}$ & $M_{z}$ \\
\hline S01 & 1000 & 2000 & $\ldots$ & $\ldots$ & $\ldots$ & 100 \\
S03-II & 4000 & 12000 & 12000 & 100 & 400 & 400 \\
\hline \hline
\end{tabular}

we design different structures of the axial force element and perform a series of finite element computations so that the SGB with an optimized structure can be used for the force test in the JF12 shock tunnel with $100 \mathrm{~ms}$ test time.

In the case of S03-II, an I-beam is used to measure the axial force. In fact, based on the S03-II, the axial force element (I-beam) was further optimized and the П-beam was designed for the case of S01 (see Fig. 2(a)).

In comparing two types of beam through FEM computations, we find that the $\Pi$-beam shows the smallest interference when a load, the normal force or pitching moment, is acting on the moment center. At the same time, the $\Pi$-beam has the largest strain output of $336 \mu \varepsilon$, while the averaged strain is only $84 \mu \varepsilon$ in the case of the I-beam. This result also indicates that the $\Pi$-beam has the higher sensitivity in measuring the axial load.

\section{B. Structural analysis by FEM}

To examine the sensitivity performance of the measuring element, the strain computations were conducted in the cases of S01 and S03-II. The findings are shown in Figs. 3 and 4. The first case is the axial force of $1000 \mathrm{~N}$ (limited load) acting on the moment center of S01. In this case, the strain output of the axial force element is $336 \mu \varepsilon$, while the output of the normal force element is only $15 \mu \varepsilon$. Minimal strain is generated on the rectangular beam when an axial force of $1000 \mathrm{~N}$ is applied at the moment center of S01 (Fig. 3(a)), and vice versa (Fig. 3(b)). The effect of the axial force on the rectangular beam is very small because of the optimized axial force element. In the S03-II case, however, when the axial force of $4000 \mathrm{~N}$ (limited load) is applied at the moment center,

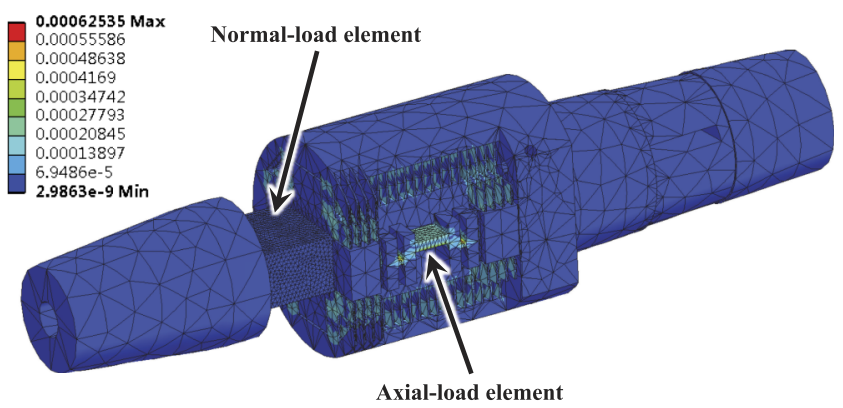

(a)

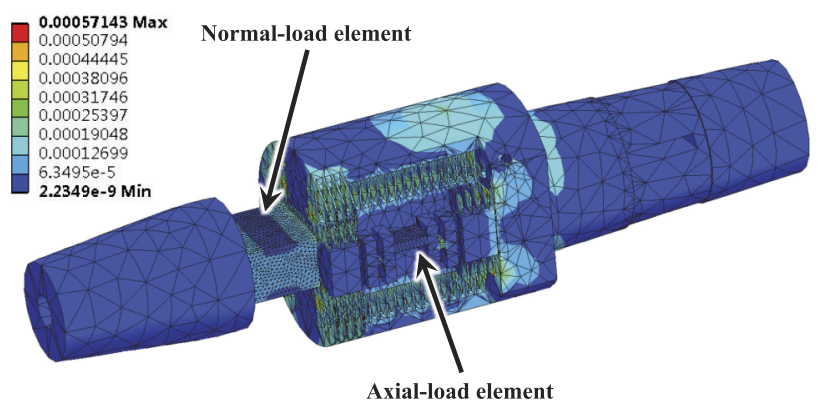

(b)

FIG. 3. Strain contours of S01 by FEM computation. (a) Axial force of $1000 \mathrm{~N}$ (Cutaway view) and (b) normal force of $2000 \mathrm{~N}$ (Cutaway view). 


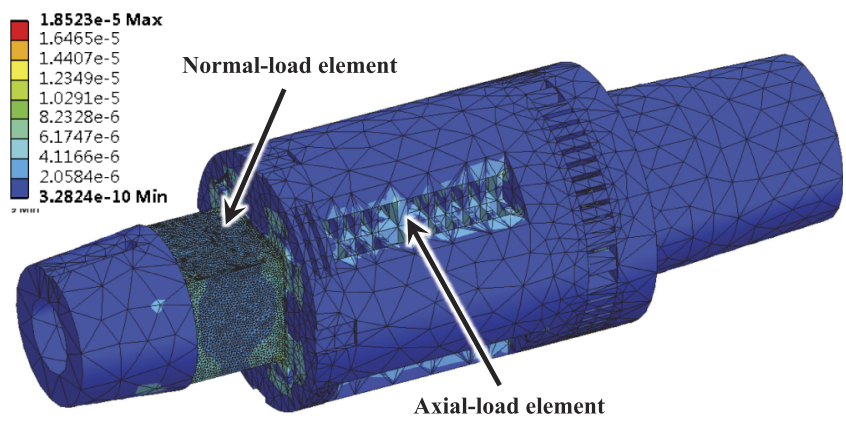

(a)

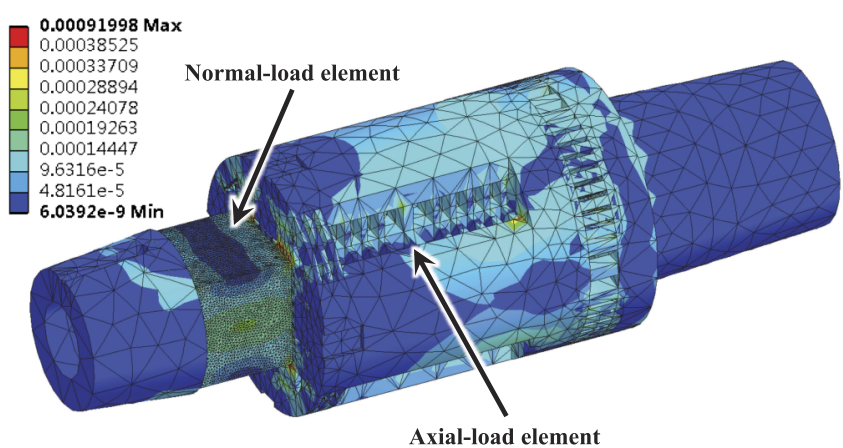

(b)

FIG. 4. Strain contours of S03-II by FEM computation: (a) axial force of $4000 \mathrm{~N}$ and (b) normal force of $12000 \mathrm{~N}$.

the strain of the rectangular element becomes $17 \mu \varepsilon$ and that of the axial load element is only $40 \mu \varepsilon$. This result means that the interference of the axial force is larger in the case of S03-II than that of S01. Additionally, the measuring sensitivity of the axial force element of S03-II is also significantly lower than that of S01.

In the same manner, we calculated the cases of the limited normal load acting on S01 and S03-II (see Fig. 4). The case of S01 shows a smaller interference from the normal force where it is less than 5\%, while the case of S03-II is more than $70 \%$.

\section{Balance calibration}

The S-series SGBs were calibrated prior to the tests on the JF12. The calibration of an internal balance involves applying known weights to the balance and recording strain-gauge readings at each force and moment combination. In this section, the calibration process is illustrated by the case of S01. In the case of sting balance S01, the calibration loads are 1920 N, 96 $\mathrm{N} \mathrm{m}$, and $960 \mathrm{~N}$ for the normal force, the pitching moment, and the axial force, respectively. The multi-component loading method was employed in this study to calibrate the present pulse-type SGB. In the multi-component loading calibration process, every component is simultaneously loaded under different load combinations. An equation that describes the relation between the loading and the balance signal can be constructed for every loading, with the unknown coefficients of the calibration formula. The calibration formula of the balance is obtained by solving the set of calibration equations. ${ }^{18}$

The mathematical modeling of the calibration relates the aerodynamic component $F$ to functions of the strain-gauge bridge reading $\mathrm{R}$ (see Eq. (1)). The system is multivariate and consists of a linear combination of nine functions of $R$. These functions are called basis functions and correspond to $R_{1}, R_{2}, R_{3}, R_{1} R_{1}, R_{1} R_{2}, R_{1} R_{3}, R_{2} R_{2}, R_{2} R_{3}, R_{3} R_{3}$. In the case of $\mathrm{S} 01$, each of the three aerodynamic components possesses nine adjustable parameters. The dependence of the model on its parameters $\mathrm{a}$ and $\mathrm{b}$ is linear,

$$
F_{i}=\sum_{j=1}^{3} a_{i, j} R_{j}+\sum_{j=1}^{3} \sum_{k=j}^{3} b_{i, j, k} R_{j} R_{k}
$$

While one of the objectives in design of strain-gauge balances is to minimize interactions between bridges, i.e., the unwanted bridge output resulting from a load applied to a different bridge, it is generally not possible to eliminate them completely. Such interactions may be classified as either "linear" or "non-linear." The linear terms typically result from such things as construction variations (manufacturing tolerances and misalignments arising during assembly of multi-part balances), improper positioning and alignment of the strain-gauges, variations of gauge factor, etc. The nonlinear terms are attributable to misalignments resulting from the complex deflections which occur when the balance is loaded.

For the S01 with three components, at each of the 76 loadings (total loading number), the bridge outputs are read several times and the mean values and standard deviations are computed. Table III shows the calibration matrix of S01, where the small interactions between bridges are indicated by the values of the cross-product terms. In the cases of S03-II and the other S-series SGBs used in JF12, the same definition and method were employed to calibrate the balances. Table IV shows the calibration matrix of S03-II. To compare with the $\mathrm{S} 01$, it is clear that the interactions of the high-order terms are larger in the case of S03-II.

Tables V and VI show the calibration performances (i.e., the error and the repeatability) of the S01 and S03-II by the static calibration. The structures of the present balance show good accuracy and precision in the static calibration. The tables show that the axial force of S01 has the highest accuracy and precision because of the optimized measuring element. Almost the close errors of the normal force were obtained for the two balances because of the same structure of measuring element, i.e., the rectangular beam.

TABLE III. Calibration matrix of sting balance S01.

\begin{tabular}{lccc}
\hline \hline & $Y$ & $M_{z}$ & $X$ \\
\hline$Y$ & $1.8948 \times 10^{3}$ & $4.3758 \times 10^{-6}$ & $3.1455 \times 10^{-3}$ \\
$M_{z}$ & $-5.1255 \times 10^{-1}$ & $1.2899 \times 10^{1}$ & $2.0600 \times 10^{-1}$ \\
$X$ & $1.2730 \times 10^{-3}$ & $1.9250 \times 10^{-4}$ & $2.0492 \times 10^{2}$ \\
$Y^{2}$ & $3.1270 \times 10^{-7}$ & $5.3816 \times 10^{-8}$ & $-6.5705 \times 10^{-7}$ \\
$M_{z}{ }^{2}$ & $-5.9041 \times 10^{-5}$ & $3.7358 \times 10^{-6}$ & $3.0362 \times 10^{-5}$ \\
$X^{2}$ & $1.1324 \times 10^{-6}$ & $2.3377 \times 10^{-8}$ & $-1.5179 \times 10^{-7}$ \\
$Y * M_{z}$ & $9.2902 \times 10^{-6}$ & $4.8693 \times 10^{-7}$ & $-5.1159 \times 10^{-5}$ \\
$Y * X$ & $-2.8996 \times 10^{-7}$ & $-2.2484 \times 10^{-8}$ & $2.3994 \times 10^{-7}$ \\
$M_{z} * X$ & $1.9249 \times 10^{-5}$ & $7.7543 \times 10^{-7}$ & $1.4646 \times 10^{-6}$ \\
\hline
\end{tabular}


TABLE IV. Calibration matrix of sting balance S03-II.

\begin{tabular}{lcccrrr}
\hline \hline & $M_{y}$ & $Z$ & $M_{z}$ & \multicolumn{1}{c}{$Y$} & \multicolumn{1}{c}{$M_{x}$} & \multicolumn{1}{c}{$\mathrm{X}$} \\
\hline$M_{y}$ & $1.3425 \times 10^{-2}$ & $6.0093 \times 10^{-2}$ & $1.6286 \times 10^{-3}$ & $-1.1155 \times 10^{-1}$ & $-3.0421 \times 10^{-3}$ & $-2.6991 \times 10^{-1}$ \\
$Z$ & $-3.7980 \times 10^{-4}$ & $7.3167 \times 10^{-1}$ & $-3.4855 \times 10^{-5}$ & $1.3476 \times 10^{-2}$ & $1.0762 \times 10^{-3}$ & $2.7555 \times 10^{-2}$ \\
$M_{z}$ & $1.8915 \times 10^{-3}$ & $2.2108 \times 10^{-1}$ & $1.3482 \times 10^{-2}$ & $2.3933 \times 10^{-1}$ & $-4.4083 \times 10^{-3}$ & $-4.6004 \times 10^{-2}$ \\
$Y$ & $8.6509 \times 10^{-6}$ & $-4.0200 \times 10^{-3}$ & $4.3184 \times 10^{-4}$ & $7.2663 \times 10^{-1}$ & $-8.2119 \times 10^{-4}$ & $1.7940 \times 10^{-5}$ \\
$M_{x}$ & $5.7801 \times 10^{-3}$ & $2.0560 \times 10^{-1}$ & $-1.1893 \times 10^{-2}$ & $-4.7279 \times 10^{-1}$ & $2.2080 \times 10^{-2}$ & $-1.2040 \times 10^{-1}$ \\
$X$ & $2.4139 \times 10^{-4}$ & $7.1616 \times 10^{-3}$ & $3.0401 \times 10^{-4}$ & $-6.2139 \times 10^{-3}$ & $-8.2397 \times 10^{-5}$ & $2.3066 \times 10^{-1}$ \\
$M_{y}^{2}$ & $0.0000 \times 10^{0}$ & $-1.4433 \times 10^{-4}$ & $9.2082 \times 10^{-7}$ & $-1.0101 \times 10^{-4}$ & $1.8717 \times 10^{-6}$ & $-4.3879 \times 10^{-5}$ \\
$Z^{2}$ & $3.0408 \times 10^{-7}$ & $0.0000 \times 10^{0}$ & $-7.3506 \times 10^{-8}$ & $-8.1227 \times 10^{-7}$ & $-6.0479 \times 10^{-10}$ & $-2.6793 \times 10^{-6}$ \\
$M_{z}^{2}$ & $-2.6006 \times 10^{-6}$ & $-7.4233 \times 10^{-5}$ & $0.0000 \times 10^{0}$ & $2.0348 \times 10^{-4}$ & $-1.7076 \times 10^{-5}$ & $-1.5384 \times 10^{-5}$ \\
$Y^{2}$ & $-3.3710 \times 10^{-9}$ & $2.5720 \times 10^{-7}$ & $1.7097 \times 10^{-7}$ & $0.0000 \times 10^{0}$ & $1.2975 \times 10^{-7}$ & $2.8749 \times 10^{-6}$ \\
$M_{x}^{2}$ & $-1.3365 \times 10^{-5}$ & $2.6547 \times 10^{-4}$ & $5.4335 \times 10^{-6}$ & $1.5910 \times 10^{-3}$ & $0.0000 \times 10^{0}$ & $-1.1815 \times 10^{-4}$ \\
$X^{2}$ & $-1.7107 \times 10^{-7}$ & $-1.1094 \times 10^{-5}$ & $-4.8058 \times 10^{-7}$ & $-4.6880 \times 10^{-7}$ & $-1.7453 \times 10^{-7}$ & $0.0000 \times 10^{0}$ \\
\hline \hline
\end{tabular}

\section{EXPERIMENTAL DESCRIPTION}

The force tests were conducted in the JF12 shock tunnel to check the performance of the pulse-type sting balances, which use the strain-gauge sensor to measure the force. In the tests, the average stagnation pressure was $2.5 \mathrm{MPa}$ and the average stagnation temperature was $2200 \mathrm{~K}$. These conditions resulted in an average freestream Mach number of 7 and an average unit Reynolds number of approximately $0.8 \times 10^{6} \mathrm{~m}^{-1}$. In addition, the model was supported by a tail sting mounted on the support mechanism in the test section. The force tests were conducted at nominal angles of attack $5^{\circ}$ with zero sideslip angle.

In the experiments, two cones with $10^{\circ}$ semivertex angle were used; these were made of aluminum alloy and were $0.75 \mathrm{~m}$ and $1.5 \mathrm{~m}$ long, respectively. The balances S01 and S03-II were used for the smaller and larger cones, respectively, in the force tests (Fig. 5). The cone is the standard model and has data available in the literature. The reference area and dimensions of the models are presented in Table VII, including the models of the China Academy of Aerospace Aerodynamics ${ }^{19}$ and National Aeronautics and Space Administration (NASA). ${ }^{20,21}$

\section{FORCE TESTS}

\section{A. Balance signal analysis}

Force tests were conducted for the dynamic calibration of the S-series balances using two cones.

Figure 6 shows the Pitot pressure variation at the nozzle exit. Obviously, the test time is more than $100 \mathrm{~ms}$ based on the time history of the Pitot pressure. The balance signals (only the normal and axial forces) obtained by S01 and S03-II are shown in Figures 7 and 10.

TABLE V. Combining loading error (\%).

\begin{tabular}{lcccccc}
\hline \hline Serial no. & $X$ & $Y$ & $Z$ & $M_{x}$ & $M_{y}$ & $M_{z}$ \\
\hline S01 & 0.03 & 0.26 & $\ldots$ & $\ldots$ & $\ldots$ & 0.12 \\
S03-II & 0.222 & 0.248 & 0.38 & 0.43 & 0.034 & 0.054 \\
\hline \hline
\end{tabular}

Figure 7 shows the balance voltage signals of the normal force. The case of S03-II shows minimal response (strain output) because of the rectangular beam with large size and high stiffness. Moreover, the frequency of S03-II is also higher than that of S01. The signals were processed at the time range of $96 \mathrm{~ms}$. The two frequencies, i.e., $30.52 \mathrm{~Hz}$ and $61.04 \mathrm{~Hz}$, were found using Fast Fourier Transformation (FFT) analysis in the case of S01 (see Fig. 7(a)). Obviously, at least three cycles can be found during the $100 \mathrm{~ms}$ test time. Therefore, the averaging method can be used in the data postprocessing.

Additionally, prior to the shock tunnel run, the threedimensional designs of the MBS system are modeled (see Fig. 8). A series of computations, including the static structure, dynamics, and modal analysis, is conducted by using FEA. The numerical results can be used to estimate the experimental results, such as the vibrational frequency and cycle number of the MBS system, during the limited test time. Based on FEA of the MBS system, the modal frequencies in the normal direction, 34 and $46 \mathrm{~Hz}$, can be obtained for the cases of S01 and S03-II, respectively. FEM results have a good agreement with the force tests and FEA successfully predicted the vibration performance of the MBSS. Figure 9 shows the results of FEM simulations, which are the modal vibration in the normal direction, for the cases of S01 and S03-II. The modal vibration in the normal direction directly affects the signal frequencies of the normal force and the pitching moment. In this study, the modal frequency of MBS system, $f \geq 2 / t \mathrm{~Hz}$ (here, $t$ is the test time, e.g., $t$ is approximately $100 \mathrm{~ms}$, then $f$ should be equal and greater than $20 \mathrm{~Hz}$ ), is used as a design criterion, where at least the two cycles can be found in the balance signal. A comparison of the axial signals (see Fig. 10) shows that the S01 has the largest signal output, which means that its measuring sensitivity is high because of the optimized structure of the axial element. Thus, the measurement capability of the axial

TABLE VI. Combining loading repeatability (\%).

\begin{tabular}{lcccccc}
\hline \hline Serial no. & $X$ & $Y$ & $Z$ & $M_{x}$ & $M_{y}$ & $M_{z}$ \\
\hline S01 & 0.03 & 0.03 & $\ldots$ & $\ldots$ & $\ldots$ & 0.05 \\
S03-II & 0.137 & 0.229 & 0.256 & 0.186 & 0.082 & 0.071 \\
\hline \hline
\end{tabular}



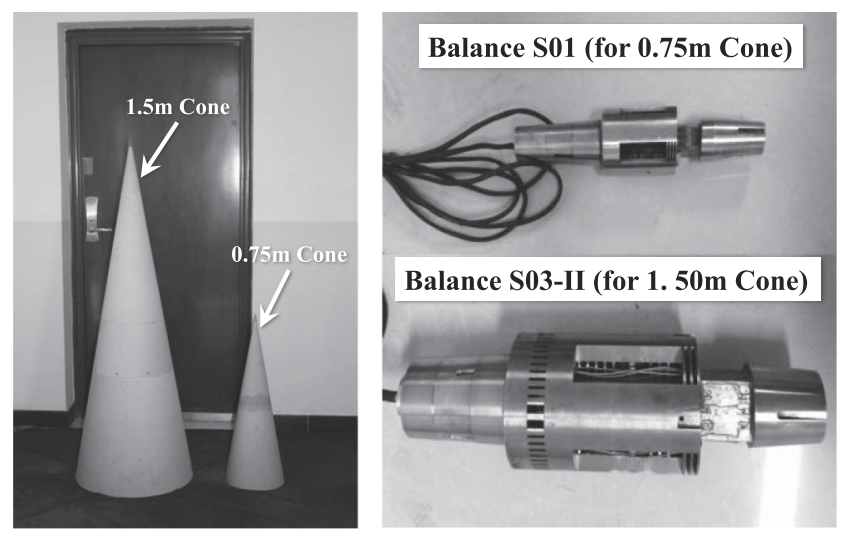

FIG. 5. Two large-scale cones and S-series balances used in the present force tests.

TABLE VII. Dimensions of the cones used in different wind tunnels.

\begin{tabular}{llcc}
\hline \hline Test wind tunnel & Length $(\mathrm{m})$ & Reference area $\left(\mathrm{m}^{2}\right)$ & Weight $(\mathrm{kg})$ \\
\hline JF12 & 0.75 & 0.0549 & 6.9 \\
JF12 & 1.5 & 0.2198 & 29.5 \\
FD-03 & 0.14178 & 0.00196 & $\ldots$ \\
Langley 11-in. & 0.0855 & 0.0007 & $\ldots$ \\
\hline \hline
\end{tabular}

force is obviously better than that of the normal force in the force tests using the present S-series SGBs. The large oscillation of the normal force has minimal effects on the axial force element of S01.

Therefore, the test results suggest that S-series SGBs fully comply with the requirements for the force test during the 100 ms test.

\section{B. Aerodynamic force results}

Figure 11 presents a comparison of the test results for $\mathrm{S} 01$ and S03-II. Some data were obtained by other conventional hypersonic wind tunnels (the theoretical result was obtained by Cheng's cone theory ${ }^{22}$ ). The results have good agreement with the data on Langley 11-in. $\left(T_{0}=630 \mathrm{~K}\right)^{20,21}$ and FD-03 $\left(T_{0}\right.$ $=600 \mathrm{~K}){ }^{19}$ wind tunnels. In the case of NASA, Mach number is 6.8 and Reynolds number $(\mathrm{L})$ is $0.81 \times 10^{6}$. A comparison with the NASA data shows that the normal and axial force coefficients decreased by $2.61 \%$ and $4.69 \%$, respectively, in the case of S01. For the hypersonic shock tunnel and large test model, based on the mentioned flow conditions, the test results are acceptable. Furthermore, good repeatability was observed during the shock tunnel testing (see Table VIII). As shown in Table VIII, the balance S01 shows good performance in terms

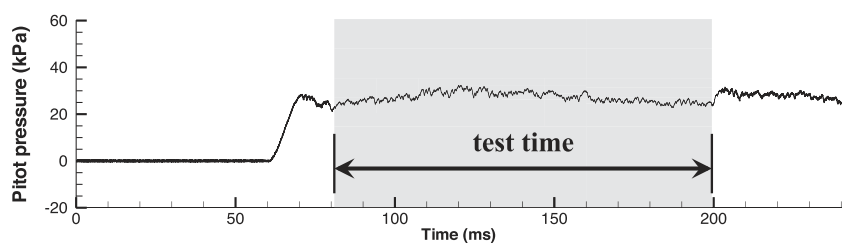

FIG. 6. Time history of Pitot pressure (range of test time is marked gray).

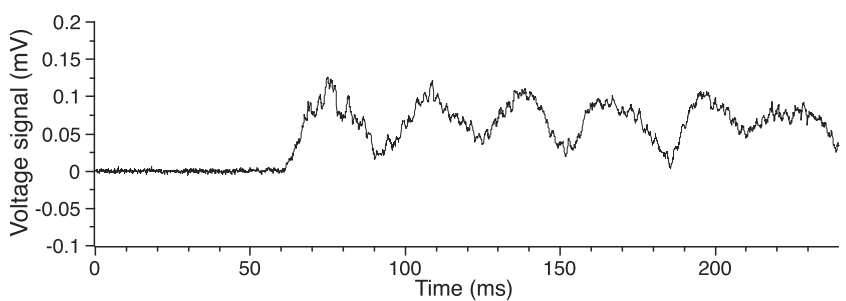

(a)

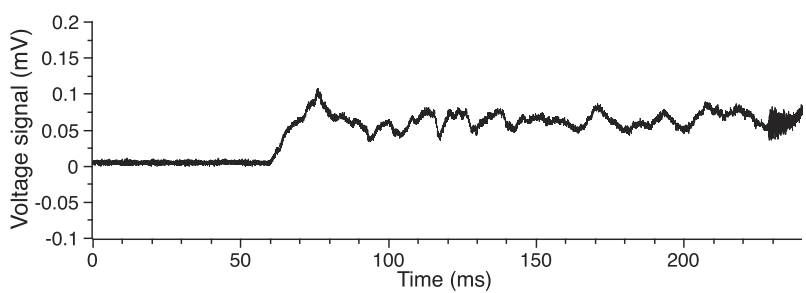

(b)

FIG. 7. Voltage signals of normal force by the S01 and S03-II. (a) S01 signal and (b) S03-II signal.

of test precision. Equation (2) is used to calculate the standard deviation $\sigma$,

$$
\sigma_{R}=\sqrt{\sum_{i=1}^{n} \frac{\left(R_{i}-\bar{R}\right)^{2}}{n-1}},
$$

where $\bar{R}$ is the averaged value of some aerodynamic coefficient of $n$ tests; in this study, $n \geq 5$.

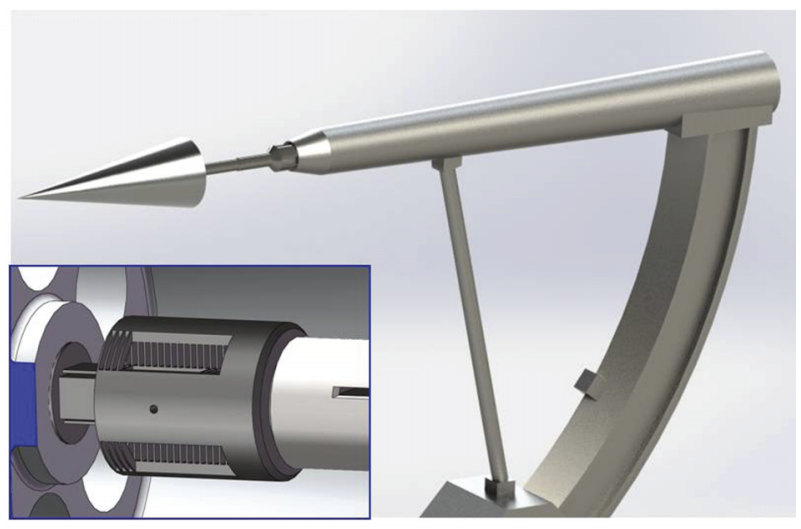

(a)

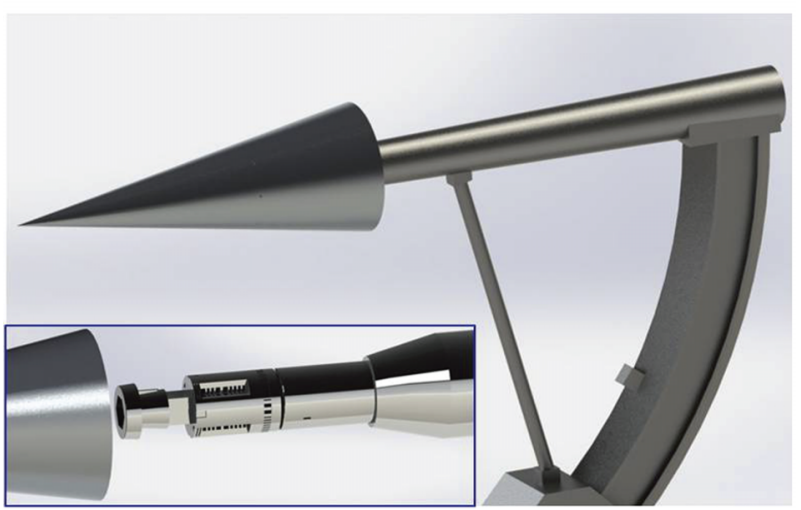

(b)

FIG. 8. Three-dimensional modeling of the MBS system. (a) MBS system with S01 and (b) MBS system with S03-II. 


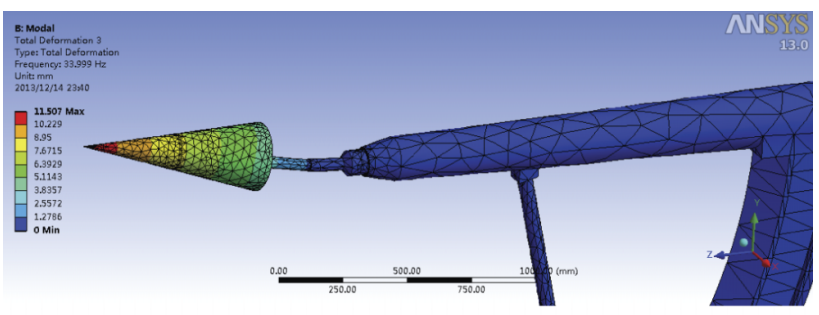

(a)

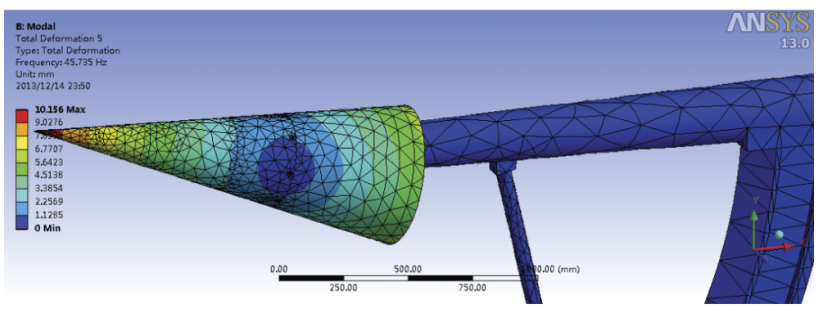

(b)

FIG. 9. FEM simulations of the MBS system (modal vibration in the normal direction). (a) MBS system with S01 and (b) MBS system with S03-II.

\section{Uncertainty analysis}

Measurement uncertainty is a complex subject that involves both statistical techniques and engineering judgment. A aerodynamic force measurement is influenced by many factors, particularly in a shock tunnel. The short test time requires fast response of instrumentation and measuring structure (MBS system). These issues have implications for the uncertainty analysis. Based on a preliminary analysis, the effects (error sources) on the results of the force test can be summarized as follows: (1) the shock tunnel, (2) the calibration of SGB, (3) the test model, and (4) the measurements.

The axial force coefficient, $C_{A}$, can be calculated by the following equation:

$$
C_{A}=\frac{X}{q S} .
$$

The methodology of the measurement uncertainty is as follows: ${ }^{23}$

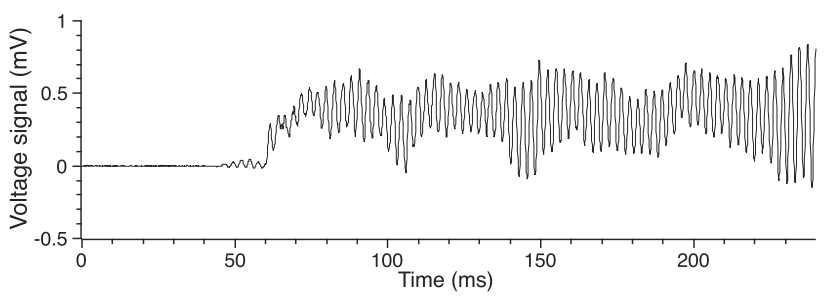

(a)

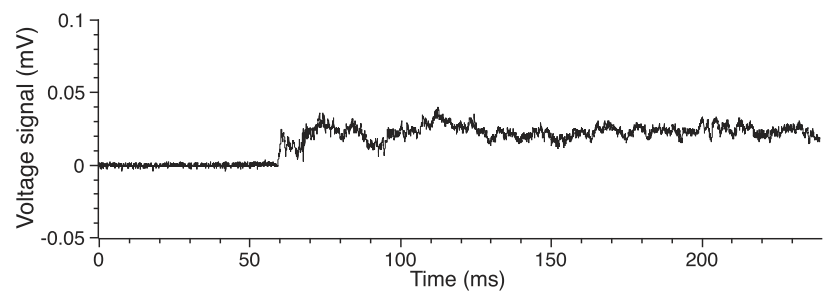

(b)

FIG. 10. Voltage signals of axial force by the S01 and S03-II. (a) S01 signal and (b) S03-II signal.

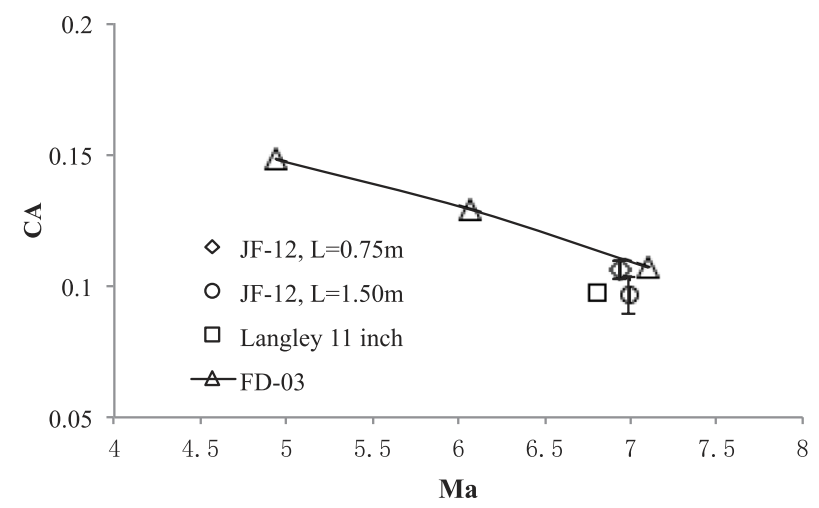

(a)

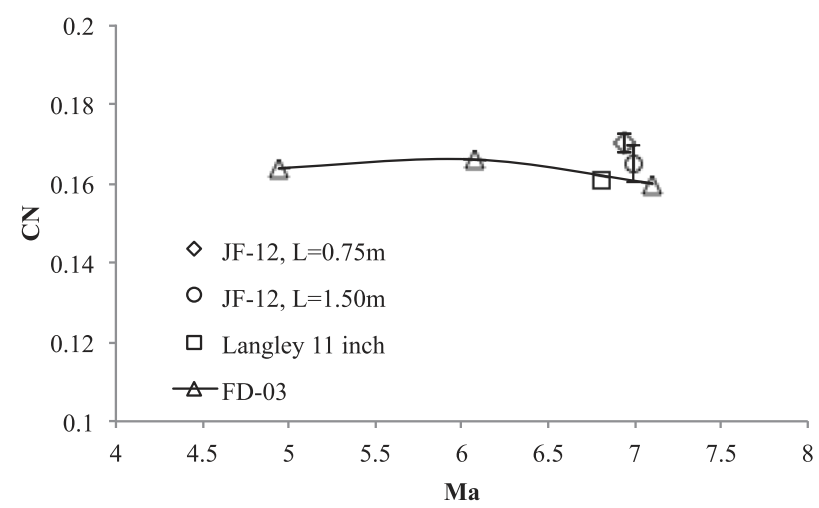

(b)

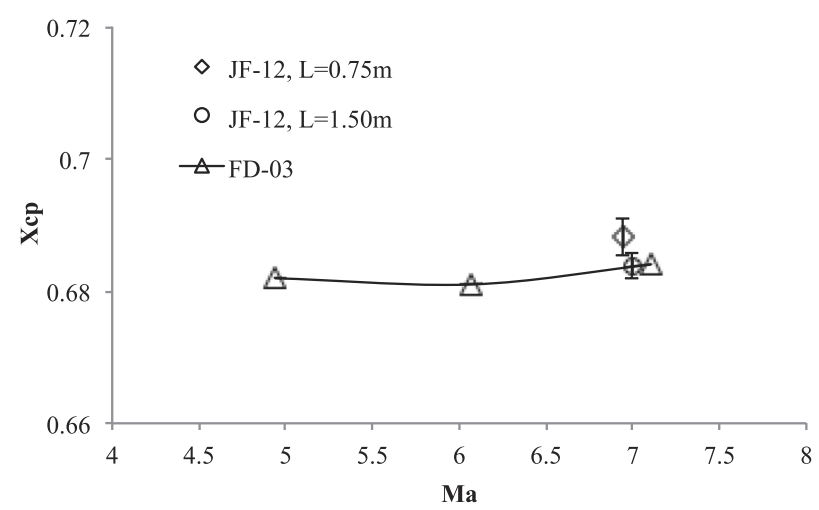

(c)

FIG. 11. Aerodynamic coefficient comparison and center of pressure for S01 (for $0.75 \mathrm{~m}$ cone) and S03-II (for $1.5 \mathrm{~m}$ cone). (a) Axial force, (b) normal Force, and (c) center of pressure.

1. The measurement system is defined and the data reduction equations are determined.

2. The sources of uncertainty for each individual measurement are identified.

3. The relative significance of the uncertainty sources is assessed.

TABLE VIII. Repeatability of force test.

\begin{tabular}{lcccc}
\hline \hline S-series SGB & $\sigma_{C_{N}}$ & $\sigma_{C_{M}}$ & $\sigma_{C_{A}}$ & $\sigma_{X_{C p}}$ \\
\hline S01 & 0.00242 & 0.00186 & 0.00337 & 0.00283 \\
S03-II & 0.00482 & 0.00415 & 0.00717 & 0.00199 \\
\hline \hline
\end{tabular}


TABLE IX. Uncertainty results of force coefficients obtained by S01 and S03-II.

\begin{tabular}{lccr}
\hline \hline S-series SGB & $U_{C_{A}}$ & $U_{C_{N}}$ & $U_{C_{M}}$ \\
\hline S01 & $\pm 9.880 \% C_{A}$ & $\pm 8.566 \% C_{N}$ & $\pm 8.647 \% C_{M}$ \\
S03-II & $\pm 13.184 \% C_{A}$ & $\pm 9.412 \% C_{N}$ & $\pm 10.140 \% C_{M}$ \\
\hline \hline
\end{tabular}

4. The precision, $P$, and bias, $B$, for each significant error source are estimated. The total bias and precision are then obtained as the root-sum-square of each contributor.

5. The precision and bias limits are propagated into the test results and combined into total uncertainties.

To take $C_{A}$ as an example, therefore, the relative uncertainty in $C_{A}$ can be written as ${ }^{24-26}$

$$
U_{C_{A}}= \pm \sqrt{P_{C_{A}}^{2}+B_{C_{A}}^{2}},
$$

where $P_{C_{A}}$ and $B_{C_{A}}$ are the precision limit and bias limit of $C_{A}$, respectively.

Table IX shows the uncertainty of test results obtained by S01 and S03-II, respectively. As shown in Table IX, the results for S01 have higher accuracy in the axial component because of the improved measuring element. The test results suggest that the accuracy of S-series SGBs should be high enough for the force measurement in the JF12 shock tunnel. The data uncertainties indicate that the test results can be considered acceptable because the force test was conducted in a hypersonic shock tunnel, where the aerodynamic force is unsteady during the test run. The present accuracy and precision of test data substantially increase because the test duration is more than $100 \mathrm{~ms}$.

\section{CONCLUSIONS}

S-series pulse-type SGBs were designed and optimized for the force tests in the JF12 shock tunnel with long test duration. The range of the maximum load (the normal force of SGB) is from $500 \mathrm{~N}$ to $12000 \mathrm{~N}$ for the test models with different scales. Two sting pulse-type SGBs were compared and analyzed in the aspects of FEM calculation, static calibration, and output signal. The S01, with the optimized axial load element, shows good performance in the force tests of JF12, where its accuracy and precision increase as a result of the higher measuring sensitivity. In addition, the large oscillations of the normal loads have minimal effects on the axial load signal because of the structural optimization. S-series balances were used in the force tests of two large-scale cones in the JF12 shock tunnel. The test results show good agreement with the other wind tunnel data. The structural performance of S-series SGBs fully complies with the requirements of force measurements during $100 \mathrm{~ms}$, especially the measuring capability of the axial load. Therefore, the S-series SGB with optimized structure can be used in the force tests in the JF12 hypersonic shock tunnel with long test duration.

\section{ACKNOWLEDGMENTS}

This work was supported by the National Natural Science Foundation of China (Grant No. 11302232).

${ }^{1}$ P. Arrington, R. Joiner, and A. Henderson, NASA TN D-2489, 1954.

${ }^{2}$ L. Bernstein, AGARDograph No. 214, 1975.

${ }^{3}$ K. Naumann, H. Ende, G. Mathieu, and A. George, AIAA J. 31, 1068 (1993).

${ }^{4}$ K. Naumann and H. Ende, AIP Conf. Proc. 208, 653 (1990).

${ }^{5}$ R. Joarder and G. Jagadeesh, Shock Waves 13, 409 (2003).

${ }^{6}$ S. Saravanan, G. Jagadeesh, and K. Reddy, Shock Waves 18, 425 (2009).

${ }^{7}$ N. Sahoo, D. Mahapatra, G. Jagadeesh, S. Gopalakrishnan, and K. Reddy, Meas. Sci. Technol. 14, 260 (2003).

${ }^{8}$ M. Robinson, J. Schramm, and K. Hannemann, CEAS Space J. 1, 45 (2011).

${ }^{9}$ S. Sanderson, J. Simmons, and S. Tuttle, AIAA Paper No. 91-0540, 1991.

${ }^{10}$ D. Mee, W. Daniel, and J. Simmons, AIAA J. 34, 590 (1996).

${ }^{11}$ F. Seiler, G. Mathieu, A. George, J. Srulijes, and M. Havermann, in 25th International Symposium on Shock Wave (Bangalore, India, 2005).

${ }^{12} \mathrm{P}$. Wey, M. Bastide, B. Martinez, J. Srulijes, and P. Gnemmi, in Proceedings of the 28th Aerodynamic Measurement Technology, Ground Testing and Flight Testing Conference (New Orleans, USA, 2012).

${ }^{13} \mathrm{~B}$. Martinez, M. Bastide, and P. Wey, in Proceedings of the 30th Aerodynamic Measurement Technology and Ground Testing Conference (Atlanta, USA, 2014).

${ }^{14}$ H. Tanno, T. Komuro, K. Sato, K. Fujita, and S. Laurence, Rev. Sci. Instrum. 85 (2014).

${ }^{15}$ H. Tanno, T. Komuro, K. Sato, K. Itoh, and T. Yamada, AIAA Paper $2013-$ 2979, 2013.

${ }^{16}$ S. Laurence and S. Karl, Exp. Fluids 48, 949 (2010).

${ }^{17}$ E. Marineau, M. MacLean, E. Mundy, and M. Holden, J. Spacecraft Rockets 49(3), 474 (2012).

${ }^{18}$ American Institute of Aeronautics and Astronautics, "Recommended practice: Calibration and use of internal Strain-Gage balances with application to wind tunnel testing," AIAA Paper 2003-R-091, 2003.

${ }^{19}$ H. Zhang, Hypersonic Aerodynamic Test (National Defence Industry Press, Beijing, China, 2004).

${ }^{20} \mathrm{C}$. Ladson and T. Blackstock, NASA TN D-1473 1962.

${ }^{21}$ J. Penland, NASA TN D-840, 1961.

${ }^{22}$ H. Cheng, WADC TN 59-335 1959.

${ }^{23}$ M. E. Kammeyer, "Uncertainty analysis for force testing in production wind tunnels," in 1st International Symposium on Strain Gauge Balances, 1999.

${ }^{24}$ Fluid Dynamics Panel Working Group 15, "Quality assessment for wind tunnel testing," AGARD-AR-304, 1994.

${ }^{25}$ AIAA-Standard, "Assessment of experimental uncertainty with application to wind tunnel testing," AIAA Paper No. 99-S-071A, 1999.

${ }^{26}$ American Institute of Aeronautics and Astronautics, AIAA-Guide, "Assessing experimental uncertainty," AIAA S-071A-1999 (AIAA Paper 2003-G045, 2003). 